\title{
Stability of Hydromorphone Hydrochloride and Morphine under Different Clinical Infusion Conditions
}

L. PING, HOU JUAN, RUI-LIN LI, Z. Y. FENG, XIA-JIN ZHOU, M. F. LIU, BAI JING AND LIU JIANG*

The Fourth Hospital of Hebei Medical University, Shijiazhuang, Hebei 050011, China

November-December 2019

Indian Journal of Pharmaceutical Sciences 
The primary objective of present study was to evaluate the stability of hydromorphone hydrochloride injection as well as to compare the stability of hydromorphone and morphine under different infusion conditions. Hydromorphone hydrochloride and morphine hydrochloride injections were dissolved in $0.9 \%$ sodium chloride and stored in patient-controlled analgesia pump, glass bottles and ordinary syringes (polyvinyl chloride) at $25^{\circ}$ and $37^{\circ}$. The concentrations of 0.05 and $0.025 \mathrm{mg} / \mathrm{ml}$ were used, which were clinical conventional intrathecal doses in this hospital. Samples were collected at $0,1,2,3,5,7,9,11,13$ and 15 days and analyzed using high performance liquid chromatography. At each time point, the appearance and $\mathrm{pH}$ values of the solutions were also examined, which indicated that hydromorphone hydrochloride injection and morphine hydrochloride injection stored in the infusion sets made of different materials for 15 d showed no significant changes either at $25^{\circ}$ or $37^{\circ}$. The high performance liquid chromatography analysis indicated that the concentrations of both drugs were maintained at greater than $90 \%$ of their initial concentrations on day 0 either at room temperature or body temperature. Hydromorphone hydrochloride injection and morphine hydrochloride injection were stable at least for 15 days when dissolved in normal saline in polyvinyl chloride infusion bag, non-polyvinyl chloride infusion bag and patient-controlled analgesia pump either at room temperature or body temperature.

Key words: Hydromorphone, morphine, patient-controlled analgesia pump, stability, PE infusion bag, PVC infusion bag

Hydromorphone hydrochloride, a semisynthetic opioid analgesic is an effective alternative to morphine, which acts primarily on $\mu$ opioid receptors. Hydromorphone is a derivative of morphine but is 5 to 10 times more potent ${ }^{[1-2]}$. It crosses the blood brain barrier faster, resulting in quicker onset and peak of analgesic activity and has fewer side effects. Therefore, hydromorphone is suitable for long-term use in patients with cancer pain, especially in elderly patients ${ }^{[3]}$.

On one hand, the intrathecal administration of hydromorphone and morphine can avoid the side effects associated with systemic administration such as constipation, nausea and vomiting. If the patients are willing and able to control the use of opioid analgesics when they have an outbreak of pain, the use of patientcontrolled analgesia (PCA) pump for pain relief is the option. On the other hand, PCA is an analgesic drug delivery device that allows patients to administer their own analgesia intermittently. It can avoid fluctuations in blood concentration levels resulting in significant improvement in analgesic effects. The workload of medical staff is also reduced. Continuous application of PCA improves the quality of life of patients in clinical practice. But there has also been some concern about the stability of the drug solutions in the pump for intrathecal administration over a 7 day at body temperature. Morphine hydrochloride is regarded as the gold standard for opioid analgesics and its stability has

*Address for correspondence E-mail: liujiang9953@163.com been reported ${ }^{[4]}$. Hydromorphone hydrochloride differs from morphine hydrochloride by the presence of a 6-keto group and the hydrogenation of the double bond at the 7-8 position of the molecule (fig. 1). However, few data are available about the stability of the intrathecal dose of hydromorphone and morphine under different infusion conditions ${ }^{[5,6]}$. Thus, the aim of the study was to evaluate the stability of the intrathecal administration hydromorphone hydrochloride (intrathecal dose $0.05 \mathrm{mg} / \mathrm{ml}$ ) and morphine hydrochloride injection (intrathecal dose $0.25 \mathrm{mg} / \mathrm{ml}$ ) prepared in $0.9 \%$ sodium chloride and then stored in PCA (PE) pumps, glass bottles and ordinary syringes (polyvinyl chloride, $\mathrm{PVC}$ ) for a period up to $15 \mathrm{~d}$ at $25^{\circ}$ and $37^{\circ}$ to provide stability data for long-term infusion of hydromorphone by a PCA device in hospital.

The high-performance liquid chromatography (HPLC) system equipped with 515 pump and 2487 ultraviolet detector (Waters, USA) was used. TC-100 incubator was supplied by Tianjin Jinzhou Scientific Instrument Co., Ltd. E-201-C type composite pH electrode was provided by Shanghai INESA Scientific Instrument Co.,

This is an open access article distributed under the terms of the Creative Commons Attribution-NonCommercial-ShareAlike 3.0 License, which allows others to remix, tweak, and build upon the work non-commercially, as long as the author is credited and the new creations are licensed under the identical terms

Accepted 26 September 2019 Revised 26 July 2019

Received 15 April 2019 Indian J Pharm Sci 2019;81(6):1140-1146 
A

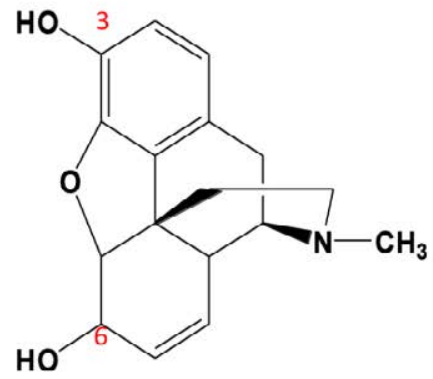

Morphine
B

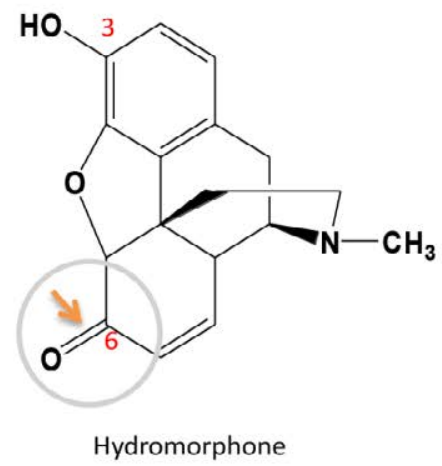

Fig. 1: Molecular structures of morphine and hydromorphone Hydromorphone (B) differs from morphine (A) by the presence of a 6-keto group and the hydrogenation of the double bond at the 7-8 position of the molecule

Ltd. AB104-S balance was supplied by Mettler Toledo, Switzerland. Disposable special liquid storage kit for wireless analgesic pump system (PE) was purchased from Jiangsu Renxian Medical Technology Co., Ltd. Fifty milliliter disposable sterile dissolution syringes (PVC) was purchased from Shandong Shingna Medical Products Co., Ltd. Hundred milliliter boric acid glass bottles were supplied by Shanghai Libao Scientific Instruments Co., Ltd.

The reference standards of hydromorphone hydrochloride (purity $>99.0 \%$, lot number: M141201, Yichang Humanwell Pharmaceutical Co., Ltd.) and morphine hydrochloride (purity $>99.0 \%$, lot number: 20150505, Qinghai Pharmaceutical Factory Co. Ltd.) were procured. Hydromorphone hydrochloride injection (2 mg, $2 \mathrm{ml}$, lot number: 1150601) was purchased from Yichang Humanwell Pharmaceutical Co., Ltd. and Morphine hydrochloride injection $(10 \mathrm{mg}, 1 \mathrm{ml}$, lot number: 151112-2) was purchased from Shenyang First Pharmaceutical Factory. Physiological saline (500 ml, $4.5 \mathrm{~g}$, lot number: 5L84G4) was provided by China Otsuka Pharmaceutical Co., Ltd. HPLC-grade methanol and acetonitrile were obtained from Thermo Fisher Scientific Co. Ltd. Analytical grade acetic acid and sodium heptane sulfonate were obtained from Beijing Mreda Technology Co., Ltd.

HPLC separation was performed on a Diamonsil C18 analytical column $(200 \times 4.6 \mathrm{~mm}, 5.0 \mu \mathrm{m})$. The mobile phase for hydromorphone consisted of $5 \mathrm{mM}$ sodium heptane sulfonate, methanol and acetic acid in the proportion of $54: 45: 1(\mathrm{v}: \mathrm{v}: \mathrm{v})$, with a flow rate of $0.8 \mathrm{ml} / \mathrm{min}$. The mobile phase for morphine consisted of a 28:72(v:v) mixture of methanol and a mixture of $1.39 \%$ acetic acid and $2.5 \mathrm{mM} / 1$ sodium heptane sulfonate, with a flow rate of $0.8 \mathrm{ml} / \mathrm{min}$. The wavelength was set at $281 \mathrm{~nm}$ for hydromorphone and $285 \mathrm{~nm}$ for morphine. The column temperature was kept $30^{\circ}$ and injection volume was $20 \mu \mathrm{l}$.

The standard stock solutions of hydromorphone hydrochloride were prepared by dissolving $0.05 \mathrm{~g}$ hydromorphone hydrochloride in $25 \mathrm{ml} 0.9 \%$ sodium chloride solution to yield a concentration of $2.0 \mathrm{mg} / \mathrm{ml}$, and were stored in sealed containers in a shaded area. The reference solutions of hydromorphone hydrochloride $(0.025,0.05,0.1,0.5$ and $1.0 \mathrm{mg} / \mathrm{ml})$ were prepared by diluting the stock solution with $0.9 \%$ sodium chloride. The standard stock solutions of morphine hydrochloride were prepared by dissolving $0.2 \mathrm{~g}$ of morphine hydrochloride in $50 \mathrm{ml}$ of $0.9 \%$ sodium chloride solution to yield a concentration of $4.0 \mathrm{mg} / \mathrm{ml}$, and were stored in sealed containers in a shaded area. The reference solutions of morphine hydrochloride $(0.1,0.3,0.5,1.0$ and $2.0 \mathrm{mg} / \mathrm{ml})$ were prepared by diluting the stock solution with $0.9 \%$ sodium chloride. Under the chromatographic conditions, the standard solutions at 5 different concentrations were measured by HPLC, and the standard curves were obtained by the peak area of concentration with external standard method.

Replicate analyses $(n=6)$ of quality control (QC) samples at 3 concentration levels $(0.025,0.05$ and $0.1 \mathrm{mg} / \mathrm{ml}$ for hydromorphone; and $0.1,0.3$ and $0.5 \mathrm{mg} / \mathrm{ml}$ for morphine) were analyzed for $3 \mathrm{~d}$ for determining the precision and accuracy of the assay method. Precision was calculated as the coefficient of relative standard deviation (RSD, \%) of the runs within a single day (intra-day) and on different days (inter-day). Accuracy was accessed by comparing the 
predicted concentrations of the QC standards using the standard curve with the theoretical concentrations. The accuracy was calculated based on drug recovery from the solvents.

A $0.05 \mathrm{~g}$ sample of hydromorphone hydrochloride $(n=6)$ was accurately weighed, and then was dissolved in $0.9 \%$ sodium chloride to reach a concentration of $0.05 \mathrm{mg} / \mathrm{ml}$. Under the above chromatographic conditions, the sample solutions were measured by HPLC. Hydromorphone hydrochloride injection ( $2 \mathrm{mg} / 2 \mathrm{ml}$ ) was diluted with $0.9 \%$ sodium chloride to reach a concentration of $0.05 \mathrm{mg} / \mathrm{ml}$ and morphine hydrochloride injection $(10 \mathrm{mg} / \mathrm{ml})$ was diluted with $0.9 \%$ sodium chloride to reach a concentration of $0.025 \mathrm{mg} / \mathrm{ml}$ (clinical conventional intrathecal dose), respectively $(n=6)$. Then the duplicate samples were stored in PCA pumps, glass bottles and ordinary syringes at $25^{\circ}$ and $37^{\circ}$. Samples were taken at $0,1,2$, $3,5,7,9,11,13$ and $15 \mathrm{~d}$, and were analyzed by HPLC. At each time point, the appearance and $\mathrm{pH}$ values of the solutions were also examined.

Retention time was $2.5 \mathrm{~min}$ for hydromorphone hydrochloride (figs. 2A, B). The regression Eqn. was $\mathrm{y}=5 \times 106 \mathrm{c}+59422, \mathrm{r}=0.99987$. The standard calibration curves exhibited good linearity over the concentration
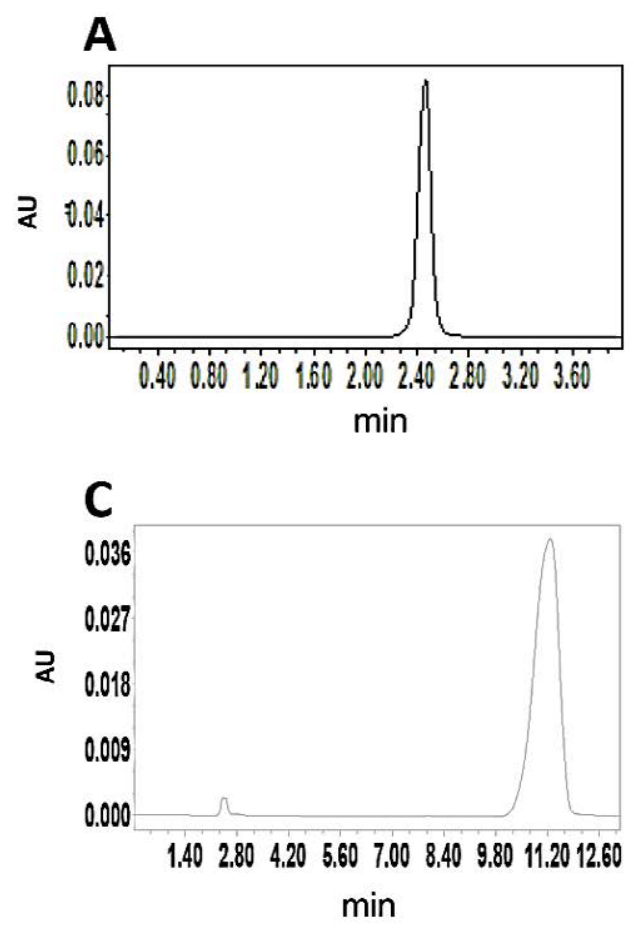

range of $0.025-1.0 \mathrm{mg} / \mathrm{ml}$. The intra-day precision (RSD, \%) was found to be 3.99, 1.46 and $1.23 \%$ at low, medium and high concentration levels, respectively. The inter-day precision was found to be $1.55-3.08 \%$. The recovery rate was $100.62 \pm 0.14,91.43 \pm 0.13$ and $101.71 \pm 0.01 \%$, respectively. Result of the replicate analyses was $0.049-0.051 \mathrm{mg} / \mathrm{ml}$, and RSD was $1.58 \%$.

Retention time was $11.2 \mathrm{~min}$ for morphine hydrochloride (figs. 2C, D). The regression Eqn was $\mathrm{Y}=6 \times 106 \mathrm{X}+18516, \mathrm{r}=0.99979$. The standard calibration curves exhibited good linearity over the concentration range of $0.1-2.0 \mathrm{mg} / \mathrm{ml}$. The intra-day precision (RSD, \%) was found to be 3.68, 2.05 and $1.78 \%$, respectively. The inter-day precision was found to be $1.32-3.01 \%$. The recovery rate was $96.25,90.56$ and $94.57 \%$, respectively, and RSD was $0.3 \%$.

Solutions of hydromorphone hydrochloride injection and morphine hydrochloride injection stored in the PCA pumps, glass bottles and ordinary syringes at $25^{\circ}$ and $37^{\circ}$ were all clear and transparent within $15 \mathrm{~d}$. No significant changes were observed in the $\mathrm{pH}$ of the solutions. The HPLC analysis showed that at $25^{\circ}$ and $37^{\circ}$, the concentrations of hydromorphone hydrochloride injection and morphine hydrochloride injection solutions maintained greater than $90 \%$ of
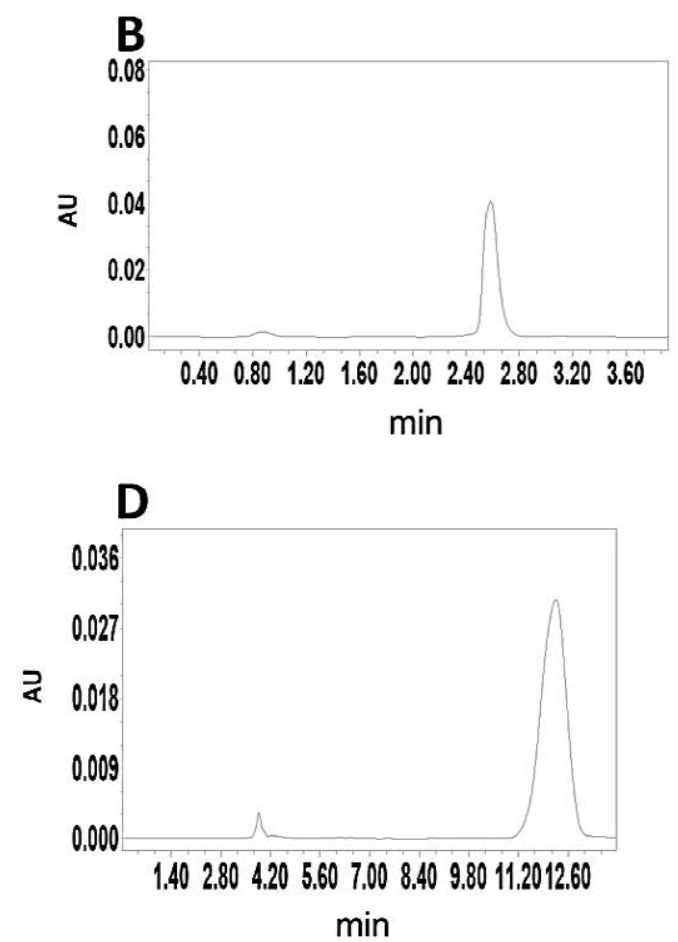

Fig. 2: HPLC chromatograms of hydromorphone hydrochloride and morphine hydrochloride (A) Solution spiked with $0.1 \mathrm{mg} / \mathrm{ml}$ standard hydromorphone hydrochloride; (B) solution spiked with $0.05 \mathrm{mg} / \mathrm{ml}$ hydromorphone hydrochloride injection; (C) solution spiked with $0.3 \mathrm{mg} / \mathrm{ml}$ standard morphine hydrochloride; and (D) solution spiked with $0.25 \mathrm{mg} / \mathrm{ml}$ morphine hydrochloride injection. The relative retention time of hydromorphone hydrochloride is $2.5 \mathrm{~min}$, and the relative retention time of morphine hydrochloride is $\mathbf{1 1 . 2} \mathbf{~ m i n}$ 
TABLE 1: pH RANGE OF HYDROMORPHONE HYDROCHLORIDE AND MORPHINE HYDROCHLORIDE SOLUTIONS

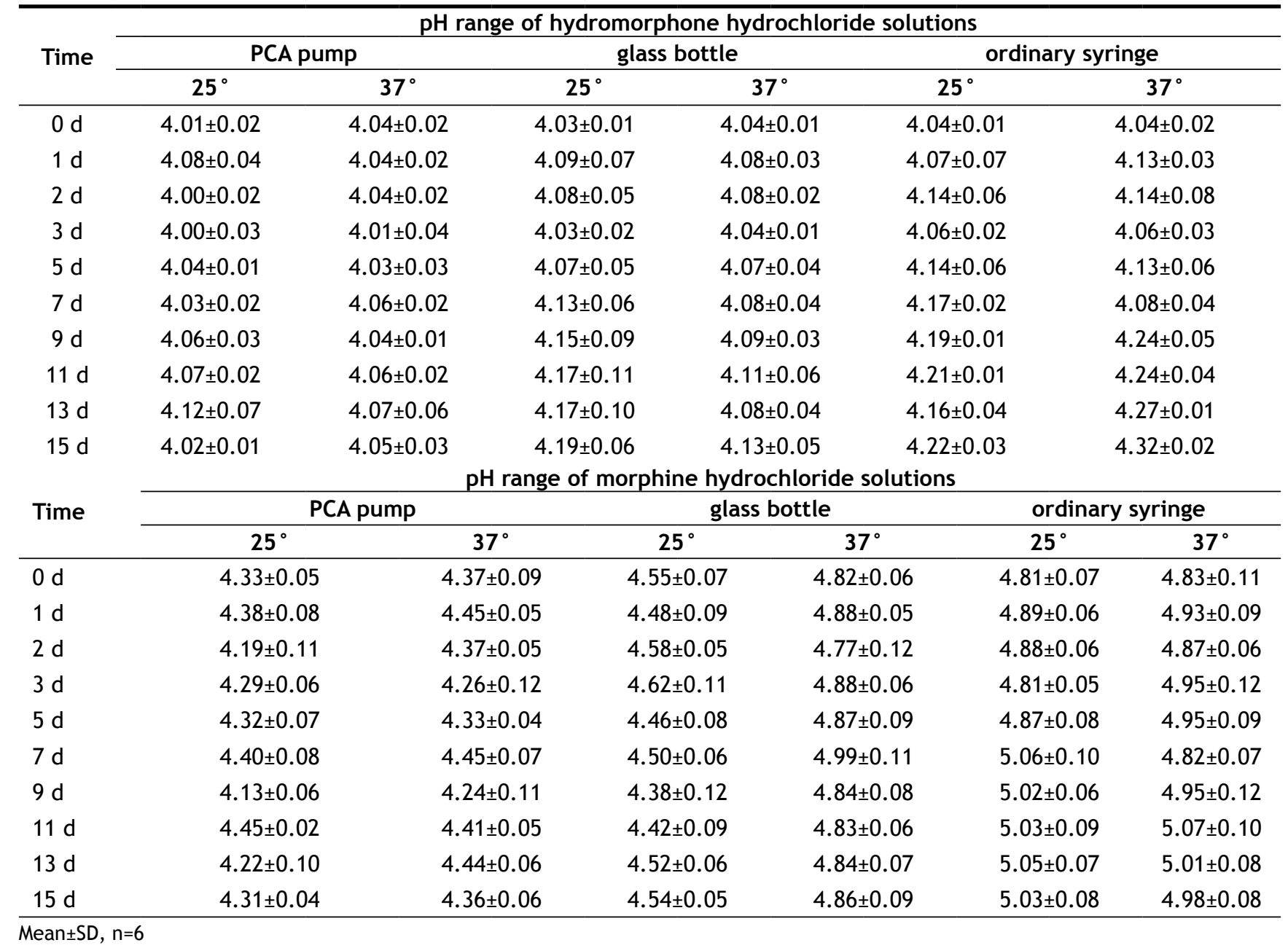

their initial concentrations on day 0 . It indicated that the solutions were stable under the test conditions. The results are shown in Tables 1 and 2.

The methods of concentration determination reported in the literature are mainly LC-MS/MS and HPLC ${ }^{[4]}$. In this study, HPLC method was used because of the economic considerations. According to the HPLC method for the determination of hydromorphone hydrochloride in the literature, different methanol-water ratios of the mobile phase were compared and screened, and the ratio of 54:45 was initially selected. To improve the peak shapes and extend the retention time, $5 \mathrm{mmol} / \mathrm{l}$ sodium heptane sulphonate was used as an ion-pair reagent, the peak of hydromorphone hydrochloride appeared early at about $2.5 \mathrm{~min}$. But the peak shape was not good when changing mobile phase. Moreover, the reagent is pure with no interference from other components, so it is considered that this peak time of $2.5 \mathrm{~min}$ is feasible. Since toohigh alkalinity levels can cause trailing phenomenon, acetic acid was used to adjust the $\mathrm{pH}$ value to about 3.1. After these improvements, sharp, symmetrical peaks, minimal baseline drift and good separation of sample were obtained. Therefore, the mobile phase was determined as a mixture of methanol-water of $54: 45$ and $5 \mathrm{mmol} / 1$ sodium heptane sulfonate with acetic acid as $\mathrm{pH}$ modifier. Using the mobile phase in domestic and foreign literature and pharmacopoeia, the chromatographic peak shape of morphine was not good and the baseline was unstable. Then the determination method from the manufacturer of morphine injection solution was used ${ }^{[4]}$, stable baseline, good separation, and sharp peak could be obtained.

The major challenges in examining the stability of this drug were, whether long-term infusion can be performed in patients when body temperature increases; and the influence of infusion sets made of different materials on the drug. The long-term stability of morphine has been established, and morphine remains stable at room temperature for $12 \mathrm{~d}, 6 \mathrm{w}$ and $3 \mathrm{mo}^{[7-9]}$ and at $37^{\circ}$ for $90 \mathrm{~d}$ according to different studies ${ }^{[10]}$. Donnelly et al.$^{[11]}$ reported the physical compatibility of high-concentration bupivacaine with hydromorphone 
TABLE 2: DETERMINATION OF THE CONTENT OF HYDROMORPHONE HYDROCHLORIDE AND MORPHINE HYDROCHLORIDE

\begin{tabular}{|c|c|c|c|c|c|c|}
\hline \multirow{3}{*}{ Time } & \multicolumn{6}{|c|}{ Concentration $\left(\times 10^{-3} \mathrm{mg} / \mathrm{ml}\right)$ hydromorphone hydrochloride } \\
\hline & \multicolumn{2}{|c|}{ PCA pump } & \multicolumn{2}{|c|}{ glass bottle } & \multicolumn{2}{|c|}{ ordinary syringe } \\
\hline & $25^{\circ}$ & $37^{\circ}$ & $25^{\circ}$ & $37^{\circ}$ & $25^{\circ}$ & $37^{\circ}$ \\
\hline $0 \mathrm{~d}$ & $50.3 \pm 1.3$ & $50.5 \pm 1.8$ & $49.9 \pm 0.9$ & $50.2 \pm 1.1$ & $49.8 \pm 2.1$ & $47.9 \pm 1.7$ \\
\hline $1 \mathrm{~d}$ & $50.0 \pm 1.5$ & $50.5 \pm 2.5$ & $49.8 \pm 1.6$ & $50.1 \pm 1.5$ & $49.9 \pm 1.8$ & $47.7 \pm 2.3$ \\
\hline $3 d$ & $48.7 \pm 1.2$ & $50.1 \pm 0.8$ & $49.6 \pm 1.8$ & $49.4 \pm 1.7$ & $48.2 \pm 2.0$ & $46.7 \pm 2.0$ \\
\hline $5 d$ & $48.2 \pm 1.8$ & $50.0 \pm 1.2$ & $49.1 \pm 1.6$ & $49.4 \pm 1.6$ & $47.9 \pm 1.7$ & $46.6 \pm 1.7$ \\
\hline $7 d$ & $48.0 \pm 1.7$ & $50.0 \pm 1.7$ & $48.6 \pm 2.3$ & $48.3 \pm 2.4$ & $47.7 \pm 1.3$ & $46.3 \pm 0.9$ \\
\hline $9 d$ & $48.0 \pm 0.8$ & $49.9 \pm 2.3$ & $47.6 \pm 2.6$ & $48.1 \pm 1.3$ & $47.2 \pm 2.4$ & $46.3 \pm 2.4$ \\
\hline $11 \mathrm{~d}$ & $47.5 \pm 1.3$ & $49.7 \pm 0.7$ & $46.8 \pm 1.7$ & $48.1 \pm 2.6$ & $46.1 \pm 2.2$ & $45.0 \pm 2.2$ \\
\hline $13 d$ & $47.8 \pm 2.0$ & $48.5 \pm 0.9$ & $46.6 \pm 0.9$ & $47.9 \pm 1.4$ & $45.7 \pm 1.6$ & $44.5 \pm 1.9$ \\
\hline \multirow[t]{2}{*}{$15 d$} & $47.5 \pm 1.1$ & $48.6 \pm 2.2$ & $46.1 \pm 1.4$ & $47.0 \pm 0.8$ & $45.5 \pm 1.9$ & $43.4 \pm 1.6$ \\
\hline & \multicolumn{6}{|c|}{ Concentration $\left(10^{-3} \mathrm{mg} / \mathrm{ml}\right)$ morphine hydrochloride } \\
\hline \multirow[t]{2}{*}{ Time } & \multicolumn{2}{|c|}{ PCA pump } & \multicolumn{2}{|c|}{ glass bottle } & \multicolumn{2}{|c|}{ ordinary syringe } \\
\hline & $25^{\circ}$ & $37^{\circ}$ & $25^{\circ}$ & $37^{\circ}$ & $25^{\circ}$ & $37^{\circ}$ \\
\hline $0 \mathrm{~d}$ & $254.2 \pm 5.3$ & $253.1 \pm 8.2$ & $249.9 \pm 7.6$ & $249.5 \pm 9.3$ & $269.1 \pm 2.4$ & $254.5 \pm 1.3$ \\
\hline $1 \mathrm{~d}$ & $254.2 \pm 4.6$ & $251.2 \pm 7.0$ & $248.5 \pm 7.8$ & $247.3 \pm 7.2$ & $269.1 \pm 2.2$ & $254.4 \pm 1.3$ \\
\hline $3 d$ & $251.2 \pm 4.2$ & $250.9 \pm 7.3$ & $240.2 \pm 6.5$ & $246.9 \pm 8.9$ & $269.1 \pm 2.2$ & $254.7 \pm 0.4$ \\
\hline $5 d$ & $250.4 \pm 6.8$ & $250.6 \pm 9.7$ & $230.5 \pm 6.9$ & $246.9 \pm 7.1$ & $267.4 \pm 1.9$ & $255.1 \pm 1.1$ \\
\hline $7 d$ & $241.4 \pm 4.8$ & $248.7 \pm 6.9$ & $231.5 \pm 8.3$ & $240.2 \pm 8.0$ & $237.3 \pm 6.8$ & $249.8 \pm 0.4$ \\
\hline $9 \mathrm{~d}$ & $241.1 \pm 6.4$ & $247.5 \pm 7.1$ & $229.6 \pm 6.4$ & $237.6 \pm 9.2$ & $247.6 \pm 2.8$ & $247.4 \pm 1.6$ \\
\hline $11 \mathrm{~d}$ & $239.7 \pm 9.7$ & $247.4 \pm 6.4$ & $221.5 \pm 7.7$ & $234.6 \pm 7.4$ & $247.6 \pm 8.5$ & $247.7 \pm 5.8$ \\
\hline $13 d$ & $240.2 \pm 9.5$ & $247.4 \pm 9.2$ & $218.4 \pm 8.1$ & $226.7 \pm 8.0$ & $246.5 \pm 1.2$ & $234.6 \pm 5.8$ \\
\hline $15 d$ & $240.2 \pm 9.4$ & $247.0 \pm 7.3$ & $231.0 \pm 7.0$ & $226.9 \pm 7.9$ & $243.2 \pm 1.6$ & $235.4 \pm 0.6$ \\
\hline
\end{tabular}

Mean \pm SD, $\mathrm{n}=6$

at $5^{\circ}$ in polypropylene syringes and non-DHEP bags, and found a slight change in the $\mathrm{pH}$ value, color, appearance of the mixture. Furthermore, it has been reported that concentration of hydromorphone solution stored at $37^{\circ}$ for $16 \mathrm{w}$ is more than $95 \%$ of the baseline value, which indicated that hydromorphone solution was stable ${ }^{[12]}$. The present study was the first attempt to investigate the stability of the intrathecal dose of hydromorphone hydrochloride injection and morphine hydrochloride injection at different temperatures in infusion sets made of different materials, and revealed that the solutions remained clear and transparent within $15 \mathrm{~d}$ showing no significant change of the appearance. The HPLC analysis showed that the concentrations of hydromorphone hydrochloride injection and morphine hydrochloride injection solutions maintained greater than $90 \%$ of their initial concentrations on day 0 either at room temperature or body temperature. Because this study was conducted under dark condition, the decrease in concentration of solutions may be related to the adsorption of infusion sets using different materials ${ }^{[12]}$. In addition, this study found that the stability of morphine hydrochloride injection was similar with hydromorphone injection. Results of sterility tests of hydromorphone showed the solution was sterile within about $10 \mathrm{~d}$ but these data are still in the research stage. However, some reported studies have shown that hydromorphone is sterile for $14^{[13]}$ and $7 \mathrm{~d}^{[14]}$ in the sterility test.

In this study, the stability of hydromorphone hydrochloride injection and morphine hydrochloride injection was investigated in PCA (PE) pumps, glass bottles and ordinary syringes (PVC) as well as the influence of storage time and temperature on their stability. The results indicated that hydromorphone hydrochloride and morphine hydrochloride injection were stable at least for $15 \mathrm{~d}$ when dissolved in normal saline solution in different infusion bag either at room temperature or body temperature. This study is the first attempt to simulate the concentration of hydromorphone hydrochloride injection $(0.05 \mathrm{mg} / \mathrm{ml})$ and morphine hydrochloride injection $(0.25 \mathrm{mg} / \mathrm{ml})$ for intrathecal administration in population, which provides the basis for the injection at a constant speed by a PCA pump for $15 \mathrm{~d}$. 


\section{REFERENCES}

1. Liu $\mathrm{R}, \mathrm{Hu} \mathrm{XL}, \mathrm{Yi} \mathrm{H}$. Progress in clinical research on hydromorphone hydrochloride. J China Prescription Drug 2014;12(3):119-21.

2. Felden L, Walter C, Harder S, Treede RD, Kayser H, Drover $\mathrm{D}$, et al. Comparative clinical effects of hydromorphone and morphine :a meta-analysis. Br J Anaesth 2011;107(3):319-28.

3. Oldenmenger WH, Lieverse PJ, Janssen PJJM, Taal W, van der Rijt CCD, Jager A. Efficacy of opioid rotation to continuous parenteral hydromorphone in advanced cancer patients failing on other opioids. Support Care Cancer 2012;20(8):1639-47.

4. Qu HY, Hao GT, Chen XY. Determination of hydromorphone concentration in human plasma by HPLC-MS/MS. Chin J Clin Pharmacol 2015;31(3):216-8.

5. Trissel LA, Xu QA, Pham L. Physical and Chemical Stability of Hydromorphone Hydrochloride 1.5 and $80 \mathrm{mg} / \mathrm{ml}$ Packaged in Plastic Syringes. Int J Pharm Compd 2002;6(1):74-6.

6. Walker SE, Coons C, Matte D, Deangelis C, Iazzetta J, Kolos $\mathrm{C}$, et al. Hydromorphone and morphine stability in portable infusion pump cassettes and minibags. Can J Hosp Pharm 1988;41(4):177-82.

7. Duafala ME, Kleinberg ML, Nacov C, Flora KP, Hines J, Davis $\mathrm{K}$, et al. Stability of morphine sulfate in infusion devices and containers for intravenous administration. Am J Hosp Pharm 1990;47:143-6.
8. Wulf H, Gleim M, Mignat C. The stability of mixtures of morphine hydrochloride, bupivacaine hydrochloride, and clonidine hydrochloride in portable pump reservoirs for the management of chronic pain syndromes. J Pain Symptom Manage 1994;9:308-11.

9. Vermeire A, Remon JP. Stability and compatibility of morphine. Int J Pharm 1999;187:17-51.

10. Hildebrand KR, Elsberry DD, Hassenbusch SJ. Stability and Compatibility of Morphine-Clonidine Admixtures in an Implantable Infusion System. J Pain Symptom Manage 2003;25(5):464-71.

11. Donnelly RF, Wong K. Physical Compatibility of HighConcentration Bupivacaine with Hydromorphone, Morphine, and Fentanyl. Can J Hosp Pharm 2010;63(2):154-5.

12. Hildebrand KR, Elsberry DE, Anderson VC. Stability and Compatibility of Hydromorphone Hydrochloride in an Implantable Infusion. J Pain Symptom Manage 2001;22(6):1042-7.

13. Khondkar D, Chopra P, McArter JP, Rosen JA, Li SK, Chemical stability of hydromorphone hydrochloride in patient-controlled analgesia injector. Int J Pharm Compd 2010;14(2):160-4.

14. Ensom MH, Decarie D, Leung K, Montgomery C. Stability of Hydromorphone-Ketamine Solutions in Glass Bottles, Plastic Syringes, and IV Bags for Pediatric Use. Can J Hosp Pharm 2009;62(2):112-8. 